\title{
LEGENDAMENTO PARA SURDOS NO SOFTWARE: QUE LHE FALTA?
}

\author{
ShirleiVilhalva*
}

RESUMO: O objetivo deste artigo consiste em discutir o uso de tecnologias de conversão de voz e de legendagem como recurso didático voltado aos estudantes surdos. Neste estudo são elencadas situações em que se tem o surdo, a tecnologia e um humano não surdo que também exerce uma função nesse processo, que envolve a inteligência artificial na educação, bem como o conceito de ciborgue. A análise da primeira situação foi inspirada nas vivências da pesquisadora como estudante de doutorado DINTER UNICAMP/UFMS, na Universidade Federal de Mato Grosso do Sul, em Campo Grande - MS. A discussão sobre as tecnologias, dialoga com teóricos como Buzato (2006), Monard e Baranauskas (2000), Leodoro (2017), entre outros. Aponta-se, como resultados, que as tecnologias de conversão de voz e de legendagem, embora tragam possibilidades de uma melhor interação entre o estudante surdo e os conteúdos ou conhecimentos trabalhados pelos professores, apresentam limitações no que se refere à transcrição fidedigna de vídeos, áudios ou diálogos em sala de aula. Conclui-se que os professores investigados ou demais mediadores da relação didática precisam conhecer e sinalizar essas limitações, tanto para atuarem como ciborgues, ou seja, facilitarem a interação entre o estudante surdo e a tecnologia, como para contribuírem com informações que subsidiem a melhoria de tais recursos. Por fim, aponta-se a necessidade de formulação de políticas de formação continuada de professores e demais profissionais que atuam com alunos surdos e ouvintes, com ou sem deficiências, buscando a melhoria das tecnologias e, assim, promovendo a aprendizagem.

ABSTRACT: The purpose of the article is to discuss the use of technologies to convert the voice and subtitling as didact way focused to the deaf students, under a perceptive way of cyborg concept. This study lists situations in which a deaf person, a technology, and a hearing human being who is functioning into the cyborg, relating to artificial intelligence into educational process, as well as the concept of cyborg. The analysis of the first situation was inspired through my experience as PHD student at Federal University of Mato Grosso do Sul in the city of Campo Grande - MS. A discussing about technologies, dialoging with researchers as Buzato, 2006 Monard e Baranauskas, 2000, Leodoro, 2017, Krusser, 2019, Rojo \& Barbosa, Yandong, 2020. Generating new expectations of political reforming related to continued education for teachers and other professionals who work with deaf and hearing students with and without deficiencies, seeking better technologies, so then promoting efficiency for learning.

PALAVRAS-CHAVE: Educação dos surdos, Tecnologia e educação, Língua brasileira de sinais.

KEYWORDS: Education, Deafness, Technological education.

\section{INTRODUÇÃO}

Pensar nas novas tecnologias como "oportunidades para melhorar o mundo" é, necessariamente, pensar em educação. [...] Mas educação, para muitos produtores de tecnologia, definidores de políticas e investimentos, e até mesmo pais e alunos, é um conceito um pouco vago, ligado

INTERLETRAS, ISSN $N^{o}$ 1807-1597. V. 9, Edição número 34. Outubro, 2021/ Março de 2022- p

Dossiê: Educação, infância, diversidade e ensino de língua em contexto complexo. 
apenas à capacitação técnica ou à funcionalidade do indivíduo num mundo que vai continuar sendo cada vez mais injusto (BUZATO, 2006, p. 1).

O objetivo deste artigo consiste em discutir o uso de tecnologias de conversão de voz e de legendagem como recurso didático voltado a alunos surdos, sob a perspectiva do conceito de ciborgue. Para tanto, utilizo dois exemplos de uso de aplicativos que realizam transcrições do áudio de vídeos, especificamente em situações em que se tem o surdo, a tecnologia e um humano que também exerce uma função nesse processo.

A análise da primeira situação foi inspirada em minhas vivências como estudante de doutorado, na Universidade Federal de Mato Grosso do Sul, em Campo Grande. Quando o intérprete de língua de sinais não estava presente, era necessário utilizar a função de legendamendo (legendagem) automática em tempo real do Google Docs, para que eu pudesse acompanhar as explicações do professor ou os diálogos entre professor e colegas de turma. Sem essa ferramenta, ocorreria uma grande perda em minha aprendizagem, pois eu não teria acesso ao que era discutido durante as aulas.

No segundo exemplo, analiso o procedimento de transcrição, ou seja, de legendamento legendagem automática, do vídeo "Conversa entre duas Inteligências Artificiais"1. Esse vídeo mostra um experimento divulgado em um canal do Youtube em que alguém utiliza um celular e um computador para fazer com que um "robô" dialogasse com seu clone. $\mathrm{O}$ robô, no caso, é o Cleverbot, um aplicativo que usa a inteligência artificial para simular conversas humanas, utilizando como banco de dados conversas com os próprios humanos.

Para analisar a transcrição automática do vídeo, utilizei o sistema Transcriber, a fim de compreender se a oralidade existente no vídeo foi transcrita fidedignamente, haja vista que as pessoas surdas, grupo no qual me incluo, precisam "ouvir" com os olhos.

O processo foi lento. Primeiramente, assisti várias vezes ao vídeo, que em determinados momentos exigiu uma reflexão quanto à situação da interação falada; não havendo o que acrescentar, no entanto, em relação à visualidade ${ }^{2}$.

Em seguida, gravei o áudio do referido vídeo no celular para que fosse possível usar o aplicativo Transcriber para fazer a transcrição e a compará-la com o legendamento automático.

\footnotetext{
${ }^{1}$ Disponível

em: https://www.youtube.com/watch?time_continue=30\&v=8ufRJ28M70Ihttps://transcribe.wreally.com/faq\# general-questions-1. Acesso em 10/08/2019

${ }^{2} \mathrm{O}$ vídeo possui apenas voz. Assim, não é possível utilizar as expressões faciais como apoio para captar, ao menos, fragmentos do sentido do que é falado em língua portuguesa. Ainda que, em alguns poucos momentos, o vídeo traga alguns elementos visuais que remetem ao que está sendo falado, e às vezes até palavras escritas, muitos desses elementos não são referenciados pela fala dos robôs. Nesse sentido, para o surdo, esse vídeo não é acessível, tendo em vista que não permite a compreensão do que está sendo falado. INTERLETRAS, ISSN N $N^{\circ}$ 1807-1597. V. 9, Edição número 34. Outubro, 2021/ Março de 2022- p
}

Dossiê: Educação, infância, diversidade e ensino de língua em contexto complexo. 
Porém, tanto o legendamento automático legendagem automática quanto a transcrição realizada pelo aplicativo foram insuficientes para permitir uma compreensão razoável da mensagem do vídeo. "Algo" estava fora de alcance, talvez pelo fato de me faltar a audição para saber o que de fato era falado no vídeo. Solicitei, assim, uma assessoria textual para transcrever as falas do vídeo e realizei algumas comparações entre três textos: dois pelo aplicativo Transcriber, realizados em celulares diferentes, para uma melhor comparação; e um transcrito pelo ouvido humano.

A escolha por essa situação específica justifica-se pelo fato de que a fala do robô, diferentemente da voz humana, apresenta incoerências e não possui elementos paralinguísticos que ajudem o surdo a compreender a mensagem, não há presença dos gestos ou dos sinais de língua de sinais e é impossível a leitura de palavras faladas (leitura labial $\left.^{3}\right)$. Dessa forma, torna-se possível analisar o papel do software na compreensão geral do surdo.

\title{
1 TECNOLOGIAS ASSISTIVAS EM ÂMBITO DE SALA DE AULA E/OU ATENDIMENTO REMOTO
}

Para iniciar a discussão proposta, é importante, primeiramente, conceituar Inteligência Artificial (IA). De acordo com os pesquisadores Monard e Baranauskas (2000, p. 3),

\begin{abstract}
Inteligência Artificial (IA) é um ramo da ciência da Computação (mas não exclusivamente) cujo interesse é fazer o computador pensar ou se comportar de forma inteligente. Devido a ser um tópico muito amplo, IA também está relacionada com psicologia, biologia, lógica matemática, linguística, engenharia, filosofia, entre outras áreas científicas.
\end{abstract}

A inteligência artificial, atualmente, está muito presente na vida das pessoas e de forma muito natural. Um exemplo disso são os corretores dos smartphones que completam as palavras ao serem escritas. Interessante refletir que "a IA é um sistema artificial desenvolvido para atividades inteligentes. É um processo no qual as máquinas imitam os seres humanos para usar o conhecimento para realizar certas tarefas." (YANDONG, 2020, p. 6, tradução nossa). Porém, é necessário ressaltar que a IA não tem consciência como os humanos.

No que se refere à influência da IA na evolução da escrita, Machado (2002, p. 25) aponta que, historicamente, "[...] a escrita já foi manuscrita, pictográfica, tipográfica, eletrônica e digital". O autor, abordando a "Cultura Tecnológica" de McLuhan, analisa as conquistas eletrônicas-digitais, consideradas em suas linguagens e seu sistema de escrita, apontando

\footnotetext{
3 “Conhecida como leitura labial ou leitura da fala, consiste na interpretação visual da comunicação de um falante através da decodificação dos movimentos dos lábios e das expressões fornecidas pela contração dos músculos da face". Disponível em: https://www2.camara.leg.br/a-camara/estruturaadm/gestao-na-camarados-deputados/responsabilidade-social-e-ambiental/acessibilidade/glossarios/dicionario-delibras/l/leitura-orofacial. Acesso em: 29/03/2021 INTERLETRAS, ISSN N $N^{\circ}$ 1807-1597. V. 9, Edição número 34. Outubro, 2021/ Março de 2022- p
}

Dossiê: Educação, infância, diversidade e ensino de língua em contexto complexo. 
que atualmente o destaque está no processo digital, que possibilita transformar a fala ou mesmo a língua de sinais automaticamente em escrita.

Nesse sentido, quando se trata da compreensão da língua por meio da leitura de uma fala oral transformada em escrita, é preciso levar em consideração duas premissas: 1) que o ato de ler está intrinsecamente atrelado à escrita, ou seja, uma depende da outra, pois é na existência da escrita que a leitura coexiste; 2) que, conforme Krusser (2019), a leitura de um texto escrito é uma atividade complexa e, diferentemente da fala, precisa colocar em conexão as áreas do cérebro responsáveis pelo processamento visual com as áreas responsáveis pela linguagem.

Percebe-se que, atualmente, existem vídeos que permitem a leitura de duas línguas diferentes de forma simultânea. Como exemplo, cito a utilização, no contexto do ensino remoto emergencial ${ }^{4}$ de aulas realizadas por meio de tecnologias que permitem encontros virtuais entre alunos e professores, em que, na presença de um aluno surdo, há a leitura da língua de sinais juntamente com a legenda em língua portuguesa.

Essas situações vêm gerando uma nova concepção do ato de ler os sinais da Libras (ou de outras línguas de sinais) em um contexto virtual, pois, concomitantemente, há a leitura da legenda da língua escrita, o que tem demandado para o surdo, além do processo de ler, o desenvolvimento de habilidades muito particulares, haja vista a necessidade de assistir e contextualizar para, então, compreender as informações transmitidas e/ou lidas virtualmente.

Os dois tipos de leituras dependerão da exposição da linguagem e ambiente linguístico do estudante surdo, e ele precisa ter conhecimento das duas línguas apresentadas no vídeo para que ocorra a fluidez de diferentes leituras ao mesmo tempo.

Estudos recentes vêm trazendo novas perspectivas sobre essa temática. As mudanças que estão sendo apresentadas, ainda que de forma tímida, envolvem o conceito de multimodalidade, que se caracteriza, conforme Rojo e Barbosa (2015, p. 25) "[...] pela utilização de diferentes tipos de linguagem, como, por exemplo, fotos, vídeos, ilustrações, gráficos, efeitos sonoros dos mais diversos, animações (GIFs) em um único texto.”

Por outro lado, na leitura de um texto virtual em língua de sinais, o sinalizante tende a definir o processo da leitura, sobretudo quando é uma leitura pausada e com imagem, em que se utilizam diferentes tipos de linguagens, na perspectiva da multimodalidade. Nesse sentido, Krusser (2019) aponta:

O texto em vídeos língua de sinais, o intérprete tende a definir o ritmo de leitura; os players de vídeo nem sempre oferecem recursos para marcação de partes do vídeo ou ferramentas para alterar a velocidade de reprodução; para observar uma imagem, o texto sinalizado precisa ser interrompido; para rever uma frase recém-lida, não basta direcionar o olhar; para localizar uma

\footnotetext{
${ }^{4}$ Modalidade de ensino adotada a partir de 2020 por redes de ensino públicas e privadas, frente aos protocolos de biossegurança, em que foi recomendado o isolamento social como forma de diminuir o contágio durante a pandemia do Covid-19.

INTERLETRAS, ISSN N ${ }^{o}$ 1807-1597. V. 9, Edição número 34. Outubro, 2021/ Março de 2022- p
}

Dossiê: Educação, infância, diversidade e ensino de língua em contexto complexo. 
informação ou para ter uma ideia da estrutura e da dimensão do texto, pode ser necessário um trabalho exaustivo de parar, retroceder e avançar o vídeo (KRUSSER, 2019, p. 59).

No entanto, as leituras de um vídeo em língua de sinais juntamente com um texto escrito têm sua fluidez, que dependerá também da linguagem do leitor sinalizante. Em um contexto maior, Buzato $(2018$, p. 150) considera que "[...] as línguas possuem mecanismos de modalização (amenização ou intensificação ou necessidade)", dando um suporte que, independentemente de se referir à escrita em língua portuguesa, à língua de sinais ou à escrita de língua de sinais, esses mesmos mecanismos serão encontrados nas diferentes leituras expostas aos diferentes leitores na era digital.

Nesse processo, observa-se distintas possibilidades de leituras. Entretanto, é preciso ressaltar que o transcritor, que utiliza a inteligência artificial para converter o áudio para texto, na língua ou idioma selecionado, não é uma transcrição precisa. Assim, faz-se necessário encontrar soluções que resolvam os problemas apresentados por esses mecanismos tecnológicos.

Embora se reconheça que a tecnologia vem evoluindo e sanando as dificuldades enfrentadas pelos usuários, é preciso compreender que ela ainda não alcança as expectativas almejadas. Chega-se, assim, à questão da necessidade da melhoria dos recursos e dados de composição que realizam, através de áudio nítido, uma transcrição de alta performace na escrita.

Outra ferramenta, muito utilizada por pessoas surdas falantes da língua oral ou por pessoas ouvintes, é o recurso de conversão de voz/fala em texto, em tempo real. Importante observar que, ao fazer a legendagem, o sistema primeiro converte a fala em texto, e, depois, a exibe a legenda sincronizada com a cena falada.

Historicamente, a necessidade de associar a oralidade ao texto escrito surgiu como busca de soluções para os problemas de perda de audição com o envelhecimento humano. Os humanos, ao longo da vida, têm perda auditiva significativa, passando assim por um processo em que sentem a necessidade, no convívio social, de ter segurança tanto para entender o que é dito ao seu redor como em se fazer entendidos.

Nesse sentido, a busca de melhoria vem ao encontro dos recursos tecnológicos. Por conta da moderna tecnologia, a transcrição ou até mesmo a tradução de fala para texto em tempo real alteram o conforto linguístico da pessoa surda, pessoas deficientes auditivas e pessoas com distúrbios de compreensão auditiva (pessoas que ouvem, mas não conseguem entender determinadas palavras).

\section{CONCEITO DE CIBORGUE}

O conceito de ciborgue remete à relação entre pessoas e tecnologias assistivas no campo educacional, envolvendo a situação em que professor e aluno trabalham em conjunto com essas tecnologias, como "ciborgues".

INTERLETRAS, ISSN N $N^{\circ}$ 1807-1597. V. 9, Edição número 34. Outubro, 2021/ Março de 2022- p

Dossiê: Educação, infância, diversidade e ensino de língua em contexto complexo. 
Pensando no ciborgue como um híbrido de máquina e organismo, utilizamos esse conceito dada a relação intrínseca entre a máquina e o professor na $\mathrm{EaD}$. Pensando no ciborgue como uma criatura social e ficcional, basta substituirmos a palavra ficcional por virtual e teremos a dimensão de uma prática docente que se concretiza em tempos e espaços multiplicados, que estão além do mundo físico que conhecemos até então (LEODORO, 2017, p. 9).

É importante refletir que na sala de aula, onde predomina a língua falada, o aluno surdo necessitará utilizar recursos digitais de aprendizagem. Um dos mais acessíveis é o Google $D o c s^{5}$, que atualmente se encontra disponível até mesmo no celular. No entanto, o professor precisa ter conhecimento desse recurso para auxiliar seu aluno a utilizá-lo de forma eficiente.

As tecnologias que promovem a acessibilidade ajudam a minimizar as dificuldades advindas da ausência da comunicação natural (criando um ciborgue), mas também é preciso a sensibilidade de quem está interagindo com o surdo (nesse caso o professor) para estar atento às capacidades e limitações tanto da máquina como do aluno, que podem ser gerenciadas de modo a criar um ambiente cognitivo (compreensão) que leve à aprendizagem.

Essa forma de ver a questão pode ser importante para o pensamento e para as políticas sobre educação bilíngue, porque fornece um novo modo de pensar sobre quem são os agentes que influenciam a aprendizagem, qual formação o professor necessita, que tipo de software/máquina é realmente útil e qual deve ser o caminho para que a tecnologia e a aprendizagem sejam mais bem desenvolvidas. Ressalto que, ao apontarem as limitações da máquina e as estratégias que utilizam para superá-las, professor e aluno acabam fornecendo subsídios para quem está tentando melhorar a tecnologia.

A falta do tradutor/intérprete na sala de aula suscita e intensifica a necessidade do uso da tecnologia assistiva. No caderno "O tradutor e intérprete da língua brasileira de sinais e língua portuguesa", do Programa Nacional de Apoio à Educação de Surdos, a Profa. Dra. Ronice Muller de Quadros define intérprete de língua de sinais como a "[...] pessoa que interpreta de uma dada língua de sinais para outra língua, ou desta outra língua para uma determinada língua de sinais", e o Tradutor-intérprete de língua de sinais como a "[...] pessoa que traduz e interpreta a língua de sinais para a língua falada e vice-versa em quaisquer modalidades que se apresentar (oral ou escrita)" (BRASIL, 2004, p. 7).

Conforme o art. $2^{\circ}$ da Lei $\mathrm{n}^{\circ} 12.319$, de $1^{\circ}$ de setembro de 2010 , "O tradutor e intérprete terá competência para realizar interpretação das 2 (duas) línguas de maneira simultânea ou consecutiva e proficiência em tradução e interpretação da Libras e da Língua Portuguesa" (BRASIL, 2010, p. 1).

Importante ressaltar que, assim como na $\mathrm{EaD}$, numa situação de aula presencial com um aluno surdo a ideia do ciborgue nos ajuda a entender como se estabelece a possibilidade de compreensão que leva ao aprendizado.

\footnotetext{
${ }^{5}$ Para mais informações, ver: https://support.google.com/docs/answer/4492226?hl=pt-BR INTERLETRAS, ISSN No 1807-1597. V. 9, Edição número 34. Outubro, 2021/ Março de 2022- p
}

Dossiê: Educação, infância, diversidade e ensino de língua em contexto complexo. 
Nesse sentido, a Figura 1 ilustra uma aula com professor ciborgue e uma aluna ciborgue.

Figura 1 - Ilustração do conceito de ciborgue

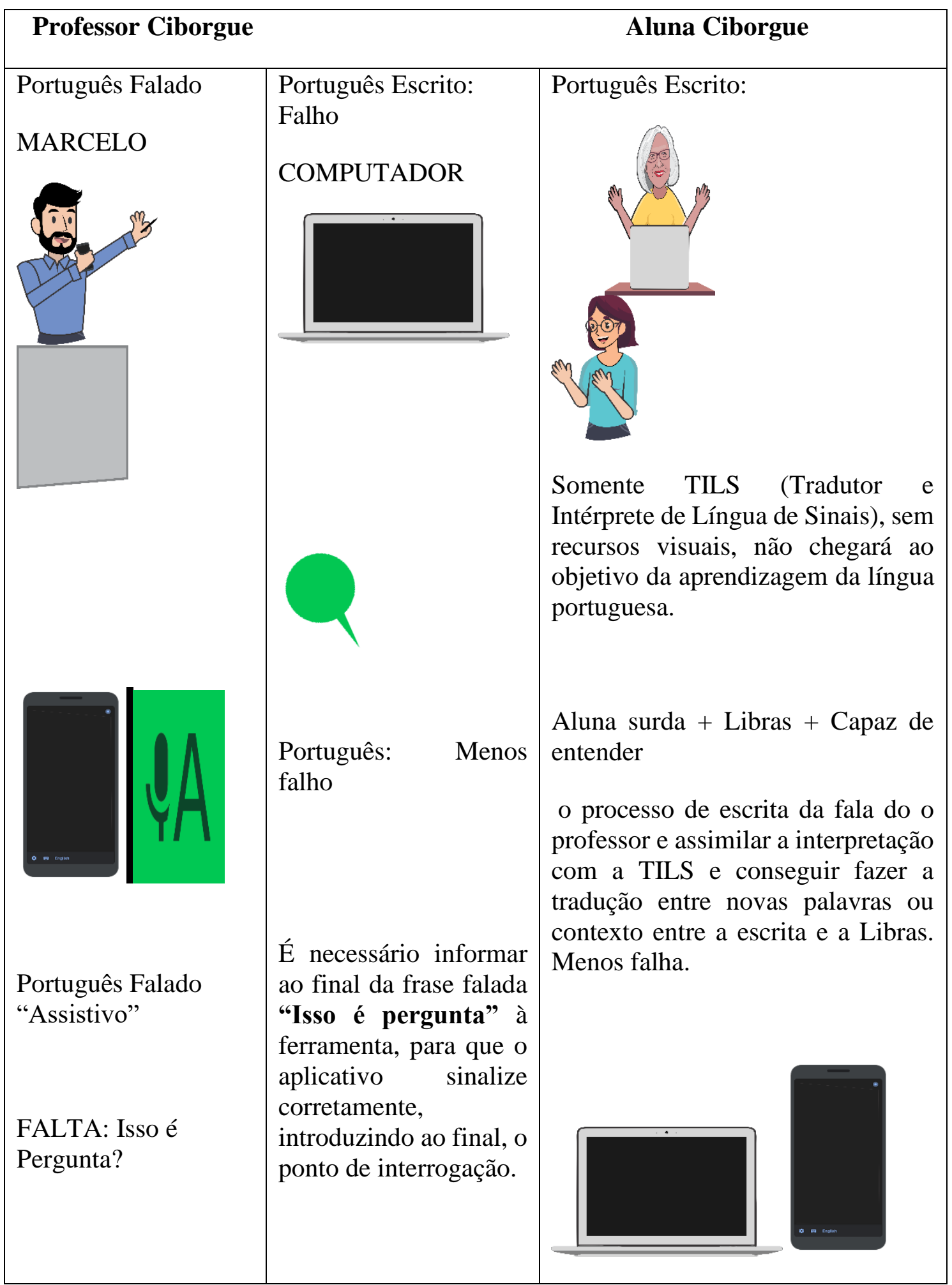

INTERLETRAS, ISSN N $N^{\circ}$ 1807-1597. V. 9, Edição número 34. Outubro, 2021/ Março de 2022- p

Dossiê: Educação, infância, diversidade e ensino de língua em contexto complexo. 


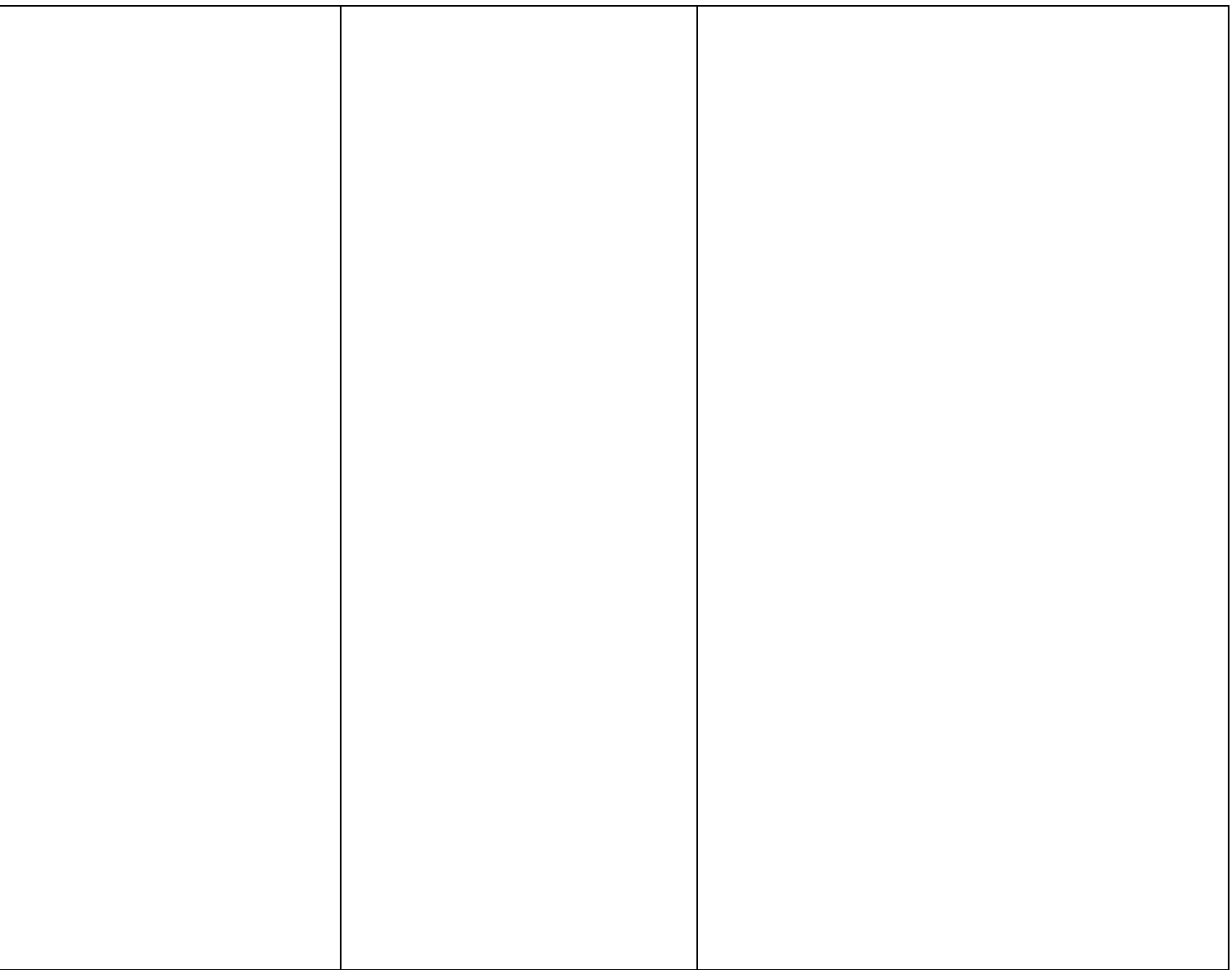

Fonte: Produção própria.

\section{RELAÇÃO ENTRE PESSOAS E TECNOLOGIAS ASSISTIVAS - OS OBSTÁCULOS PARA O ALUNO SURDO EM UMA SALA DE AULA FALADA}

Ao analisar os textos transcritos automaticamente ou legendados, encontrei muitas diferenças. Entretanto, compreendo que, sem a ferramenta da legendagem em tempo real, deixa-se de fornecer aos surdos conteúdos e informações a que têm direito.

É possível afirmar que a legenda automática dos vídeos é semelhante às produções de escritas surdas ${ }^{6}$, porque a legenda "perde" palavras e algumas vezes não identifica a palavra falada corretamente, trocando por outra de significado diferente.

Por outro lado, por não ter a audição, o surdo também não faz uma transcrição direta da fala para a escrita; antes, ele faz uma "tradução", quando possui conhecimento da Língua Portuguesa, sem saber se a palavra apresentada está correta ou não. Nesse sentido,

\footnotetext{
${ }^{6}$ Escrita surda: a estrutura da Língua de Sinais difere da Língua Portuguesa escrita, pois cada uma possui suas especificidades linguísticas e ambas são línguas na modalidade visual. A Língua de Sinais está amparada no Decreto 5626/2005 em seu artigo 14, disponível em http://www.planalto.gov.br/ccivil_03/_ato2004-2006/2005/decreto/d5626.htm. Acesso em 29 mar. 2021. INTERLETRAS, ISSN N $N^{\circ}$ 1807-1597. V. 9, Edição número 34. Outubro, 2021/ Março de 2022- p
}

Dossiê: Educação, infância, diversidade e ensino de língua em contexto complexo. 
considero importante esclarecer que os surdos usam apenas as palavras de alcance de uso sistemático para as suas produções escritas.

Em relação à escrita da legenda, é importante compreender que, inicialmente, ela é observada de forma mecânica, sem reflexão, porque apenas é assistida e não analisada em relação a estar certa ou errada, até porque se ignora a presença do som. Porém, o contexto pode ser entendido por meio das imagens, uma vez que a imagem pode representar o que está sendo falado e ir além, mostrando detalhes e podendo transmitir mensagens diretas e objetivas que levam à reflexão do que se propõe.

Penso que é relevante fazer um resgate histórico sobre a evolução da legenda. Historicamente, o legendamento em tempo real ou a tradução em tempo real, como ferramenta de acesso à comunicação, foram criados para atender diferentes eventos e exibições. A criação da ferramenta legendamento contribuiu para fornecer possibilidades de exposição do que é falado, contemplando também as pessoas surdas e deficientes auditivas. A pessoa que atua como legendador geralmente é qualificada como estenógrafa, e seu trabalho é realizado em uma máquina estenotipada ${ }^{7}$ com um teclado fonético e um software especial.

Para que esse processador se efetive e todos possam fazer uso da legendagem, seja automática ou não, é necessário que seja pensado como política pública. Assim, encontramos no Decreto $\mathrm{n}^{\mathrm{o}} 5.626 / 2005$, art. 14 - VIII, a garantia de que, para efetivar o atendimento educacional especializado, as instituições devem "[...] disponibilizar equipamentos, acesso às novas tecnologias de informação e comunicação, bem como recursos didáticos para apoiar a educação de alunos surdos ou com deficiência auditiva." (BRASIL, 2005, p. 16). Nessas considerações, é de suma importância que esse processo chegue à sala de aula e aos demais ambientes escolares.

Por meio do legendador, que realiza o processo de fazer a audição, codificar a palavra e realizar o processamento no computador em tempo real, os estudantes podem ter acesso às informações disponibilizadas em programas e eventos ao vivo, incluindo conferências, congressos, reuniões, aulas, notícias e programas nacionais e internacionais, tais como Copa do Mundo e Paraolimpíadas.

Recentemente, o Google desenvolveu uma ferramenta muito importante para a acessibilidade no sistema Android, o aplicativo Live Transcriber $^{8}$, conforme Figura 2, com o intuito de auxiliar as pessoas surdas ou com problemas auditivos. Esse aplicativo converte o áudio em texto, em tempo real, facilitando assim a comunicação da pessoa surda com aquela que não se comunica através da língua de sinais.

\footnotetext{
7 O termo "estenotipia" vem do grego "stenotypos". "Stenos" significa "curto", "abreviado" e "typos", impressão. A palavra designa a técnica pela qual se obtém o registro do que é falado por meio de uma máquina - o estenótipo. De forma simplificada, é um método de transformar rapidamente um áudio em texto. http://steno.com.br/o-que-e-estenotipia/. Acesso em 23 ago. 2019

${ }^{8}$ Mais informações sobre o aplicativo podem ser conferidas em: https://www.correio24horas.com.br/noticia/nid/android-ganha-ferramenta-que-transcreve-audio-paratexto-em-tempo-real/ acesso em: 23/08/2019.

INTERLETRAS, ISSN N $N^{\circ}$ 1807-1597. V. 9, Edição número 34. Outubro, 2021/ Março de 2022- p
}

Dossiê: Educação, infância, diversidade e ensino de língua em contexto complexo. 
Figura SEQ Figura ${ }^{*}$ ARABIC 2 - Aplicativo

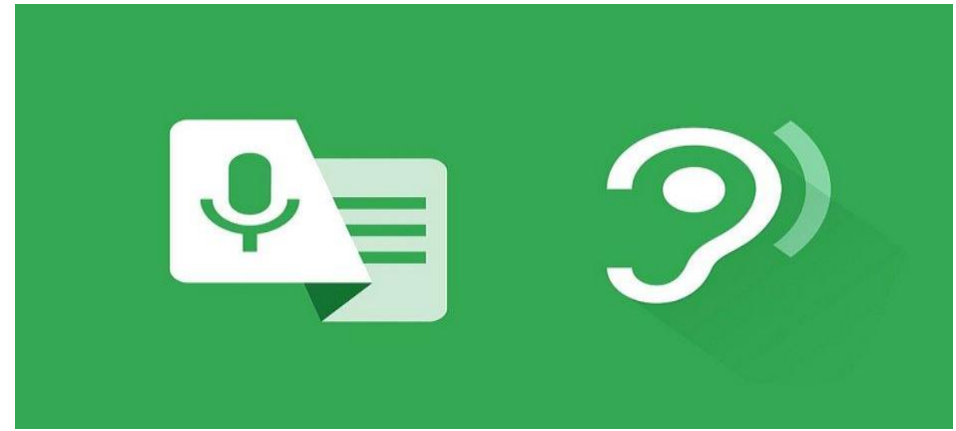

Fonte: Google Play (2021)

O áudio que o Transcriber transforma em texto apresenta o formato de legendas, que vem contemplar a pessoa surda em diferentes locais. As legendas são definidas como palavras ou textos exibidos em um vídeo, e trazem determinados tipos de informações relevantes ou mesmo significados. São muito utilizadas em filmes, vídeos ou outros tipos de mídias, tanto nas telas dos cinemas como em computadores ou notebooks pessoais, para apresentar a tradução das falas por meio de textos ou outros formatos. Em dispositivos móveis, como celulares, tablets ou smartphones, oferece essa facilidade, em tempo real, para a pessoa surda ou ouvinte, pois os aplicativos se encontram ao alcance das mãos, para uso imediato.

Para as pessoas que têm uma perda auditiva leve, as legendas podem tornar a compreensão muito mais segura, a depender das expectativas de cada um, pois pode complementar as informações recebidas por meio da audição e da visão, tornando o ato comunicativo mais acessível para quem possui déficit auditivo.

A Associação Brasileira de Normas Técnicas (ABNT) relaciona definições de diferentes tipos de legenda, como:

[...] 3.17 janela de LIBRAS: Espaço delimitado no vídeo onde as informações veiculadas na língua portuguesa são interpretadas através de LIBRAS.

3.18 legenda aberta (subtitling): Tradução escrita da língua estrangeira falada no programa, destinada à audiência que necessite da tradução. Quando disponível aparece na tela do televisor, não necessita de decodificador.

3.19 LIBRAS: Língua de natureza visual-espacial, com estrutura gramatical própria, que constitui o sistema linguístico de comunidades surdas do Brasil.

3.20 linha 21 ou 284: Linhas do sinal de vídeo utilizadas para transmitir as informações do CC, entre outras, dinâmicas ou estáticas.

3.21 pop-on (legenda instantânea): Legenda que aparece na tela de uma só vez, permanece por tempos determinados de exposição, normalmente em sincronia

INTERLETRAS, ISSN N $N^{o}$ 1807-1597. V. 9, Edição número 34. Outubro, 2021/ Março de 2022- p

Dossiê: Educação, infância, diversidade e ensino de língua em contexto complexo. 
com o áudio, e em seguida desaparece ou é substituída por outra legenda. É utilizada no sistema de CC pré-gravada.

3.22 roll-up (legenda em rolamento): Legenda que aparece na tela, linha por linha. À medida que vai sendo produzida, a linha de baixo sobe, dando lugar à nova linha. É utilizada no sistema de CC ao vivo. [...] (ABNT, 2005, p. 3).

Segundo o National Institute on Deafness and Other Communication Disorders (NIDCD) dos Estados Unidos:

\begin{abstract}
As legendas são criadas a partir da transcrição do programa. Um legendador separa o diálogo em legendas e garante que as palavras apareçam em sincronia com o áudio que elas descrevem. O software de computador codifica as informações de legenda e as combina com o áudio e o vídeo para criar uma nova fita mestra ou arquivo digital do programa. Idealmente, as legendas devem aparecer perto da parte inferior da tela - não no meio, onde as legendas mal colocadas podem cobrir o rosto do apresentador ou a cesta de basquete ou o quarterback (NIDCD, 2017, p. 1, tradução nossa).
\end{abstract}

No Quadro 1, apresento uma parte de um diálogo em sala de aula, mediado pela ferramenta "transcritor" do Google Doc. O professor, nessa situação, fala de forma mais pausada, um pouco mais devagar, para fazer a descrição.

Quadro 1 - Transcrição do diálogo de um professor realiza com recursos do Google Docs

O fato de você trabalhar com esses dados reais que você anotou é excelente trabalho ficar ótimo só precisa ter clareza de onde você quer chegar qual é o seu argumento e como o trabalho é para disciplina de Tecnologia caminho importante que você reflita não só sobre a questão do surdo, mas sobre a questão da tecnologia nessa situação então tendo um argumento claro aonde eu quero chegar buscando nos dados que você já tem os elementos que você precisa para desenvolver o argumento e dando a devida importância para a tecnologia junto com a discussão sobre o surdo e sobre o bilinguismo vai ficar muito bom [...]. Disciplina LP021 Introdução aos Estudos em Linguagens e Tecnologias - Professor Marcelo Buzato - Dinter - UFMS - 11/07/2019

Fonte: arquivo pessoal da autora.

Como foi observado acima, a falta de pontuação poderá ser resolvida com soluções tecnológicas. O software primeiramente transforma o fonema em onda sonora, em seguida transforma a onda sonora em letras. No entanto, ao interpretar a sentença falada, o software a entende como uma ação contínua, que ser por ele absorvida como uma curva melódica, uma curva de atuação. Uma de suas limitações, portanto, é que o software não consegue inserir sozinho o ponto de interrogação, o que faz com que o aluno surdo não saiba que a fala transcrita se refere a uma pergunta.

Assim, ao ensinar o estudante surdo, é necessário que o professor tenha esse conhecimento a respeito da ferramenta tecnológica utilizada, a fim de que forneça ao aluno pistas ou referências sobre o que está sendo falado. Dessa forma, ao sinalizar em sua fala essa formulação, o professor vai conseguir ajudar o surdo a entender com mais INTERLETRAS, ISSN No 1807-1597. V. 9, Edição número 34. Outubro, 2021/ Março de 2022- p

Dossiê: Educação, infância, diversidade e ensino de língua em contexto complexo. 
clareza o que está sendo falado, constituindo-se, nesse sentido, em um mediador entre o aluno surdo e o software.

O software não tem certas capacidades que o ouvinte humano tem, por exemplo, de identificar, pela curva entoacional, se um enunciado é uma pergunta ou não. Assim, para que o sistema professor+máquina+aluno possa fazer existir a compreensão, é preciso que o professor compense essa deficiência da máquina explicitando, na sua fala, em palavras, e não pela curva entoacional, que tal enunciado é uma pergunta.

No exemplo transcrito no Quadro 1, o professor Buzato atuou como um professor ciborgue. Por outro lado, foi preciso que a máquina se integrasse ao professor para chegar até mim, na compreensão da interpretação em Libras.

Nessa perspectiva, podemos observar que o professor é um ciborgue e a cibernética é uma ciência que descreve todos os seres, biológicos ou máquinas, como sistemas que funcionam à base de retroalimentação de informação do contexto, visando a certo objetivo. Como os seres são sistemas, é possível juntar mais de um ser num novo sistema, por exemplo, um organismo biológico, uma máquina e um sistema cibernético, assim formando um ser híbrido, que chamamos de ciborgue.

Quando o aluno também está atuando com outra máquina, nesse caso, como já foi dito acima, é necessário que o professor se atente em como falar para que, no legendamento em tempo real, uma pergunta seja entendida, mesmo sem o ponto de interrogação [?], haja vista que o computador não é capaz de fazer isso sem o comando realizado pelo professor. Nesse caso, o professor também passa a fazer parte da tecnologia assistiva, e, consequentemente, para o aluno surdo é de relevante importância que o processo venha solidificar a compreensão.

Portanto, é necessário realizar uma proposta de estudo específica e uma formação bilíngue para habilitar a fluência das línguas envolvidas, e também suscitar novos estudos sobre a tecnologia na atuação de professores e alunos ciborgues.

No Quadro 2, apresento uma amostra da transcrição realizada pelo aplicativo Transcriber do vídeo: "Conversas entre duas Inteligências Artificiais", em que utilizei, conforme já mencionado, dois celulares diferentes e um assessor textual, que aqui chamarei de "ouvido humano".

Foram destacadas nos excertos das falas - por meio de negrito ou letras maiúsculas palavras que apresentaram diferenças e/ou erros na escrita da transcrição. Trechos ou palavras não transcritas pelo aplicativo foram representadas pelo símbolo "[...]", haja vista que, quando há uma omissão, é importante que seja sinalizada, para não comprometer a compreensão da mensagem pelo surdo.

INTERLETRAS, ISSN $N^{\circ}$ 1807-1597. V. 9, Edição número 34. Outubro, 2021/ Março de 2022- p

Dossiê: Educação, infância, diversidade e ensino de língua em contexto complexo. 
Quadro 2 - Exemplo de diferenças e erros na transcrição de um vídeo

\begin{tabular}{|c|c|c|}
\hline $\begin{array}{l}\text { TRANSCRIBER } \\
\text { CELULAR } 1\end{array}$ & $\begin{array}{l}\text { TRANSCRIBER } \\
\text { CELULAR } 2\end{array}$ & $\begin{array}{l}\text { OUVIDO HUMANO } \\
\text { (VERSÃO CORRETA) }\end{array}$ \\
\hline $\begin{array}{l}\text { percebido que ele não é } \\
\text { pecado o motivo disso } \\
\text { acontecer é que pra ele } \\
\text { formular UMA resposta }\end{array}$ & $\begin{array}{l}\text { percebido que ele não é }[. . .] \\
\text { o motivo disso acontecer é } \\
\text { que pra ir pular NA } \\
\text { resposta }\end{array}$ & $\begin{array}{l}\text { percebido que ele não é } \\
\text { muito educado, o motivo } \\
\text { disso acontecer é que pra } \\
\text { ele formular uma resposta }\end{array}$ \\
\hline $\begin{array}{l}\text { não vai ficar perfeito você } \\
\text { sempre acaba percebendo } \\
\text { que tá conversando com } \\
{[\ldots] \text { robô }}\end{array}$ & $\begin{array}{l}\text { não vai ficar perfeito você } \\
\text { sempre acaba percebendo } \\
\text { que tá conversando com } \\
\text { vovô }\end{array}$ & $\begin{array}{l}\text { não vai ficar perfeito. } \\
\text { Você sempre } \\
\text { percebendo quaba } \\
\text { conversando com } \\
\text { robô }\end{array}$ \\
\hline $\begin{array}{l}\text { são aulas avançadas porque } \\
\text { você está fazendo perguntas } \\
\text { estranhas qual é a sua } \\
\text { bebida }\end{array}$ & $\begin{array}{l}\text { são obras avançadas porque } \\
\text { você está fazendo perguntas } \\
\text { estranhas qual é sua bebida }\end{array}$ & $\begin{array}{l}\text { são obras avançadas } \\
\text { porque você está fazendo } \\
\text { perguntas estranhas qual é } \\
\text { sua bebida }\end{array}$ \\
\hline
\end{tabular}

Fonte: produção própria.

Observando as transcrições realizadas, foi possível notar que os softwares têm dificuldade em diferenciar algumas consoantes e se saem melhor com as vogais. Possivelmente, o algoritmo procura uma palavra mais provável (segundo algum tipo de critério) e preenche as consoantes. Por exemplo, conversar com "vovô" deve ser de uso mais frequente que conversar com "robô" em textos da língua portuguesa.

Em relação às omissões, uma possível explicação para a sua ocorrência pode ser o fato de que, quando há uma "elisão" entre o final de uma palavra e o início da outra, o software não consegue captar esse som como sendo um som individual. Por exemplo, "com um robô" e "com robô". Como o "m" é uma semivogal, ela se mistura com o "u", que é vogal, na fala, então o software não "ouve" o "um". É possível que os erros tenham a ver com a "captura" dos fonemas, ou seja, é um problema de distinguir um sinal físico (o som) específico, numa cadeia de sinais físicos que são produzidos de uma forma pouco precisa, variam de pessoa para pessoa, de frase para frase, entre outros.

Então, veja que interessante: a pista visual que o surdo usa pra "completar" a informação que falta na legenda é, na verdade, uma forma de o surdo fazer esse "cálculo" de "o que seria possível/frequente estar ali naquele lugar que não posso ouvir nem ler?". Mas o surdo, por ser uma pessoa, tem linguagem natural (Libras ou outras), tem convívio cultural, tem consciência, entre outros. Dessa forma, usa-se estratégias diferentes da estratégia estatística da máquina, que não tem nada disso, apenas a capacidade de processar dados muito rapidamente.

INTERLETRAS, ISSN N $N^{\circ}$ 1807-1597. V. 9, Edição número 34. Outubro, 2021/ Março de 2022- p

Dossiê: Educação, infância, diversidade e ensino de língua em contexto complexo. 
Ao realizar as análises, foi observado que a falta de capacidade do software (Google Docs) em captar a entoação para sinalizar perguntas no primeiro caso (Quadro 1), e os erros de transcrição do Transcriber no segundo (Quadro 2), afetaram a compreensão. Por outro lado, o ser humano que se relacionava com o surdo em cada caso, o professor no primeiro, e o tradutor humano no segundo, foram diferenciais que contribuíram para que o surdo pudesse receber aquela informação integralmente, ou próximo a isso.

Nos dois casos, os erros tem a ver com a "captura" dos fonemas, ou seja, com a dificuldade do software em distinguir um sinal físico (o som) específico numa cadeia de sinais físicos que são produzidos de uma forma pouco precisa, variam de pessoa para pessoa, de frase para frase, etc.

A partir desses dados, é possível afirmar que professor e software, juntos, tornam-se um ciborgue quando o professor ajusta a sua fala, por compreender a limitação do recurso. No entanto, não se pode falar em ciborgue nas situações em que apenas há a tradução ou transcrição pelo software, sem o tradutor humano, como no exemplo da transcrição das falas de robôs pelo aplicativo Transcriber, pois, por um lado, a máquina não consegue imitar perfeitamente a entonação humana e, por outro, falta para o software a capacidade de captar nuances da fala - ainda que de robôs - que só o tradutor humano capta.

\section{CONSIDERAÇÕES FINAIS}

Este artigo teve como objetivo discutir o uso de tecnologias de conversão de voz e legendagem como recurso didático voltado a alunos surdos. Para fomentar esse debate, foi realizada pesquisa bibliográfica sobre a inteligência artificial na educação, bem como o conceito de ciborgue, a fim de argumentar sobre a importância da mediação humana ao se fazer uso de recursos de tecnologia assistiva na educação de surdos.

Para exemplificar os conceitos discutidos, utilizei a análise do procedimento de transcrição do vídeo "Conversa entre duas Inteligências Artificiais", comparando o legendagem automática do sistema Transcriber e a transcrição feita por meio da mediação humana, com vistas a compreender se a oralidade existente no vídeo foi transcrita com fidedignidade pelos sistemas de legendamento.

O presente texto relata, ainda, algumas experiências da autora como aluna surda do curso de doutorado em Linguística Aplicada, quando, em sala de aula, o professor atuou como professor ciborgue, juntamente com a tecnologia assistiva.

Foi visto que, tanto a leitura através do vídeo em língua de sinais quanto o legendamento em tempo real, contribuem para ampliar e acrescentar novas áreas de pesquisas que podem ajudar a suprir as necessidades de linguagem do surdo sinalizante de línguas de sinais.

Essas novas produções são necessárias para atender a demanda de estudantes surdos que hoje não são contemplados em sala de aula. A legendagem necessita de um sistema que INTERLETRAS, ISSN No 1807-1597. V. 9, Edição número 34. Outubro, 2021/ Março de 2022- p

Dossiê: Educação, infância, diversidade e ensino de língua em contexto complexo. 
possa pontuar o texto, em determinados momentos, e para isso é necessário que os pesquisadores invistam na criação dos algoritmos necessários.

Espero que este artigo traga contribuições para se pensar novas diretrizes educacionais para Educação Bilíngue voltada aos estudantes surdos indígenas ou não indígenas usuários de língua de sinais e deficientes auditivos não sinalizantes de língua de sinais. A proposta aqui apresentada é que o professor faça uso de plataformas digitais que possam contemplar esses estudantes, já que as línguas de instrução são processadas visualmente. Nessa visão, será necessário que a política educacional esteja atenta para a política linguística em questão.

Importante refletir que este artigo, por mostrar os obstáculos enfrentados pelos estudantes surdos desde a educação infantil, ensino fundamental, ensino médio e superior, sucinta a necessidade de formulação de políticas no que se refere à formação continuada de professores e demais profissionais que atuam com alunos surdos e não surdos, com ou sem deficiências, buscando a melhoria das tecnologias e, assim, promovendo eficiência para aprendizagem.

Este artigo contou com a contribuição da assessora textual bilíngue libras/português, Mirian Lourdes Ferreira dos Santos Silva e revisora da língua portuguesa Sandra Novaes.

\section{REFERÊNCIAS}

ASSOCIAÇÃO BRASILEIRA DE NORMAS TÉCNICAS (ABNT). NBR 15290: acessibilidade em comunicação na televisão. Rio de Janeiro: ABNT, 2005.

BRASIL. Decreto $\mathrm{n}^{\circ} 5.626$, de 22 de dezembro de 2005. Regulamenta a Lei $\mathrm{n}^{\circ} 10.436$, de 24 de abril de 2002, que dispõe sobre a Língua Brasileira de Sinais - Libras, e o art. 18 da Lei $\mathrm{n}^{\circ}$ 10.098, de 19 de dezembro de 2000. Diário Oficial da União, Brasília, p. 16, 23 dez. 2005.

BRASIL. Lei $\mathrm{n}^{\circ} 12.319$, de $1^{\circ}$ de setembro de 2010. Regulamenta a profissão de Tradutor e Intérprete da Língua Brasileira de Sinais - LIBRAS. Diário Oficial da União, Brasília, Ano CXLVII, n. 1692010, seção 1, p. 1, 2 set. 2010.

BRASIL. Secretaria de Educação Especial; Programa Nacional de Apoio à Educação de Surdos. $\mathrm{O}$ tradutor e intérprete da língua brasileira de sinais e língua portuguesa. Brasília: MEC/SEESP, 2004.

BUZATO, M. E. K. Ética e linguagem nos encontros pós-humanos. In: Congresso Internacional em Humanidades Digitais, Rio de Janeiro, 09-13 abr. 2018. Anais..., Rio de Janeiro: CPDOC/FGV, 2018.

INTERLETRAS, ISSN $N^{\circ}$ 1807-1597. V. 9, Edição número 34. Outubro, 2021/ Março de 2022- p

Dossiê: Educação, infância, diversidade e ensino de língua em contexto complexo. 
BUZATO, M. E. K. Letramentos Digitais e Formação de Professores. In: Congresso Ibero-Americano EducaRede: Educação, Internet e Oportunidades - Memorial da América Latina, 3, São Paulo, 2006. Anais... São Paulo: EducaRede, 2006.

CONVERSA entre duas inteligências artificiais. Realização do canal "Guru da Ciência". [S.L.]: Canal "Guru da Ciência", 2016. (3,33 min.), legendado. Disponível em: https://www.youtube.com/watch?v=8ufRJ28M70I\&t=30s. Acesso em: 07 abr. 2021.

KRUSSER, R. Tecnologia e Designer para facilitar a leitura em língua brasileira de sinais. In: CORREA, I.; CRUZ, C. R. (Org.). Língua Brasileira de Sinais e Tecnologias Digitais. Porto Alegre, RS: Penso, 2019.

LEODORO, S. A. P. Eu, Professora-Ciborgue: proposta de investigação sobre o ethos docente que emerge na $\mathrm{EaD}$ sob a perspectiva das metodologias ativas e da informática da dominação. In: Congresso Internacional ABED de Educação a Distância, 23, Foz do Iguaçu, 17-21 set. 2017. Anais...: Foz do Iguaçu: ABED, 2017.

MACHADO, I. Digitalização. Linguagem. Discurso. As mediações dialógicas possíveis. Lumina, Juiz de Fora, v.4/v.5, n. 2/n.1, p. 19-48, jul/dez. 2001/jan./jun. 2002.

MONARD, M. C; BARANAUSKAS, J. A. Aplicações de Inteligência Artificial: uma visão geral. 2000. Disponível em: <http://dcm.ffclrp.usp.br/ augusto/publications/2000laptec.pdf> Acesso em 15 set. 2019.

NACIONAL INSTITUTE ON DEAFNESS AND OTHER COMMUNICATION DISORDES (NIDCD). Captions for deaf and hard-of-hearing viewers. NIH Pub., New York, n. 00-4834, p. 1-4, jun. 2017. Disponível em: https://www.nidcd.nih.gov/sites/default/files/Documents/health/hearing/CaptionsForDe afViewers-508.pdf. Acesso em 07 abr. 2021.

ROJO, R. H. R.; BARBOSA, J. P. Hipermodernidade, multiletramentos e gêneros discursivos. São Paulo: Parábola Editorial, 2015.

YANDONG, C. Artificial Intelligence and Judicial Modernization. Shangai, China: Springer, 2020.

\footnotetext{
*Shirley Vilhalva - Doutoranda em Linguística aplicada - Dinter - UNICAMP/ UFMS (2019 - 2023 em andamento) Mestrado em Linguística - UFSC (2009). Professora Surda da Universidade Federal de Mato Grosso do Sul - UFMS. shivi323@ hotmail.com. https://orcid.org/0000-0002-8206-9401
}

INTERLETRAS, ISSN No 1807-1597. V. 9, Edição número 34. Outubro, 2021/ Março de 2022- p

Dossiê: Educação, infância, diversidade e ensino de língua em contexto complexo. 